\title{
PERCEPTION AND ATTITUDE TOWARDS CAESAREAN SECTION - THE VIEWS ARE CHANGING: FINDINGS AMONG ANTENATAL ATTENDEES IN A NIGER DELTA TERTIARY FACILITY
}

${ }^{1}$ Abah MG and ${ }^{2}$ Umoh AV
Department of Obstetrics and Gynaecology, University of Uyo Teaching Hospital, P.M.B 1136, Uyo, Akwa Ibom state, Nigeria

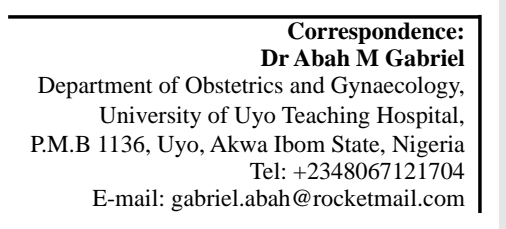

\section{INTRODUCTION}

$\mathrm{C}_{\mathrm{n}}$ aesarean section is one of the oldest procedures in Obstetric practice and may be a necessary end in the termination of pregnancy to abort or minimize complications to the mother, foetus or both. Worldwide, though unevenly distributed, it accounts for about $15 \%$ of births. ${ }^{1}$ In the developed countries, the operation of Caesarean section has become well established with ease and safety, hence there is a lure for the procedure with women opting for it, increasingly for non-medical reasons. ${ }^{2-4}$ This trend is a product of the perceived safety of the procedure, increasing societal demand for improved foetal outcome, pelvic floor protection and obstetricians' aspirations to meet these demands. ${ }^{2}$ The concern has therefore become that of a rising Caesarean section rate, their indications and the need to reduce the trend.

In the developing countries however, Caesarean section utilisation have been observed to be low. ${ }^{6}$ A significant contributor to this comparatively lower Caesarean section rate is thought to be due to negative attitudes and perception of the procedure by pregnant women. African studies have shown widespread rejection of indicated Caesarean section by women which is viewed by them as a reproductive failure. ${ }^{7}$ Despite the higher risk of uterine rupture in women with previous Caesarean section scars, some studies have shown a high default rate among these women, with some presenting to hospital only following complications during trial of vaginal birth at home, thus contributing to increase maternal and foetal morbidity and mortality. ${ }^{8}$ 
Mortality and morbidity from pregnancy and labour-related causes have been observed to be high in developing nations, especially those of sub-Saharan African region. ${ }^{9}$ Associated with these is a high perinatal complications rate including death. ${ }^{9}$ Several reasons have been given for the abysmal mortality figures. Of particular significance here are the delay models of barriers to emergency obstetric care. $^{10}$ Aversion to Caesarean section may contribute to a level-1 delay while a form of level-3 delay hardly given much consideration is refusal to give consent for an emergency and occasionally an elective Caesarean operation to be carried out. This is against the backdrop of the known right of the patient to be treated/ operated upon only after an informed consent has been obtained. ${ }^{11,12}$ The consequences of a delay in Caesarean intervention on the mother, foetus or both due to a declined consent cannot be over-emphasized.

The place of Caesarean section in comprehensive emergency obstetric care and prevention of foeto-maternal morbidity and mortality is obvious. It has been shown that there is a strong inverse association between Caesarean section rate and maternal, infant and neonatal mortality. ${ }^{1}$ There is therefore the need to appraise the procedure frequently especially with a view to evaluating factors militating against the acceptability of this lifesaving procedure. There is paucity of information regarding the attitude of women in our environment towards Caesarean section. Hence, this study was conducted to assess the perception and attitude of our pregnant women towards Caesarean section with a view to determining the barriers if any to its acceptance.

\section{SUBJECTS AND METHODS}

This cross-sectional survey was conducted from 1st January to 31st March, 2010 among pregnant women attending antenatal clinic at the University of Uyo Teaching Hospital, in the Niger Delta area of Nigeria. The minimum sample size required for this study was determined using the statistical formula for the calculation of sample size when data expected is discrete or categorical. With this, a sample size of 315 was arrived at. However, because the calculated sample size is only the minimum required and further increases beyond this aids wider distribution and reduces the margin of error even further, we used a working sample size of 500 .

Five hundred antenatal clinic attendants of the University of Uyo Teaching Hospital (UUTH), Uyo, South- south, Nigeria, were randomly selected. Verbal consent with a right to opt out was obtained after assurance of confidentiality. The women were interviewed using self-administered semi-structured, pretested questionnaires with open and close ended questions. The questionnaires inquired about their socio-demographic characteristics, opinion about Caesarean section, reasons for being in favour of or against Caesarean Section, and their possible responses if Caesarean Section became necessary during pregnancy or labour. The questionnaires were answered while in the clinic and returned on the same day before leaving the clinic to curb interferences with the answers by spouses and other relatives.

The exclusion criteria included women who declined consent for the study, those who had never previously obtained antenatal care or delivered in an orthodox health facility. The data were analysed using tables and percentages.

\section{RESULTS}

Five hundred booked pregnant women participated in the study, however 497(99.4\%) of the questionnaires were properly completed and therefore analysed. The age of the 
respondents ranged between 17 and 48years with a mean of 29.1 years (SD?). Two hundred and sixty two $(52.7 \%)$ of the respondents were between the ages of 26 and 32 years. The majority $(61.2 \%)$ of the women were Ibibios; 98.6\% were Christians, $91.1 \%$ married, $61.2 \%$ had tertiary education while $67.0 \%$ were employed. One hundred and fifty-five (31.2\%) of the respondents were nulliparous (Table I). One hundred and fifteen women (23.1\%) had had previous Caesarean delivery.

Four hundred and thirty $(86.5 \%)$ of the respondents knew Caesarean section was an operation to deliver a baby while $21(4.2 \%)$ women had no idea of what it was (Table II). Most of the respondents, 446(89.7\%) believed that Caesarean sections were sometimes necessary mainly for medical reasons and thus support and will accept it if advised in the course of pregnancy or labour. Most of these respondents considered it a safer mode of delivery when vaginal delivery is not feasible (96.0\%) (Table III)

Fifty-one(10.3\%) respondents felt Caesarean sections were unnecessary and will not accept it on any account for reasons ranging from fear of death $(33.3 \%)$, denial of womanhood (23.5\%), and possibility of being insulted by other women $(19.6 \%)$ to its being forbidden by culture (13.7\%), the devil's work(11.8\%), doctor`s self-interest $(7.8 \%)$ and $\operatorname{cost}(5.9 \%)$ (Table IV)

Amongst the respondents who had had a Caesarean delivery, all knew what Caesarean section was but $34.5 \%$ will neither support it nor accept a repeat Caesarean delivery when indicated.

\section{DISCUSSIONS}

Caesarean section (CS) is one of the most commonly performed surgical procedures the world over. ${ }^{2}$ In our study population, the majority $(86.0 \%)$ of the respondents knew that
CS was an operation performed to deliver a baby. The high knowledge of what CS by the respondents may be a product of their educational level (most of them had tertiary level of education), their parity $(68.8 \%$ had had at-least one previous delivery and thus may have benefited from previous antenatal health talks) and previous exposure to the procedure (23.1\% had a Caesarean delivery) and would therefore have been informed in the course of the pre-operative counselling about the procedure.

Previous studies in Nigeria have shown aversion of pregnant women towards CS, not only because of its associated maternal and foetal hazards but also because of the general belief that abdominal delivery is a sign of reproductive failure. ${ }^{7,13-16}$ This is in direct contrast to findings in our study where majority of the women believed that CS was sometimes necessary as a mode of delivery, mainly for medical reasons. In addition, it was also observed that, $83.2 \%$ of those who perceived it as a necessity would support and accept it whenever it is offered. This level of acceptance may probably be due to the sociodemographic characteristics of the women (majority being married and employed were less likely to show aversion due to cost) as well as information received during health talks in antenatal clinic where the advantages of CS and its role in the reduction of maternal mortality are continually explained. Most of these patients $(96.0 \%)$ considered it a safer mode of delivery when vaginal delivery is not feasible while $1.2 \%$ and $0.5 \%$ will accept to have CS to avoid the stress of vaginal delivery and to please health workers respectively. Acceptance rates of $85 \%$ and $52 \%$ were also observed among pregnant women in Ibadan and Ilesa respectively. ${ }^{17}$, ${ }^{18}$ The level of acceptance of CS in our study however contrasts with findings from a study carried out 
in two hospitals in Ile-Ife and Lagos where $81.2 \%$ of their obstetric patients showed aversion to Caesarean delivery and viewed it as a reproductive failure. ${ }^{7}$

In this study, $10.3 \%$ of the respondents believed that CS was unnecessary and will not support or accept the procedure if advised during pregnancy or labour. Reasons adduced by the women for this negative attitude included its perception as the devils work, reproductive failure/ denial of womanhood, fear of death, cost and its request being at the doctors' self-interest. Amongst the respondents who had had previous Caesarean deliveries, all agreed that CS was sometimes necessary as a mode of delivery mainly for medical reasons (95.0\%). However $34.5 \%$ of those who had had previous Caesarean deliveries despite their knowledge will not support or accept a repeat CS as a mode of delivery. However, the influence of their past experience, unfavourable outcome or implication of the procedure in terms of cost and duration of hospitalisation after the previous Caesarean section, as well as inadequate counselling by the care providers cannot be clearly ruled out. In a study in Ilesa, $45 \%$ of previous CS respondents did not support it. ${ }^{16}$ In Turkey, where trial of uterine scars was a rarity until recently, most women (80\%) who had had a Caesarean delivery were dissatisfied about the procedure and will not support the method; as $61.8 \%$ showed negative feelings ranging from simple disappointment, anger and fear to some sort of failure and jealousy. ${ }^{19}$ The difference between our finding and others above may be the product of simple variation in the study population vis-à-vis their religious/ traditional beliefs and practices. Several studies failed to show any significant influence of educational level, marital status and tribe on acceptability of CS but most agree that the reasons for aversion are mostly products of traditional beliefs and practices. ${ }^{7,13,}$ 17,18

\section{TABLE 1: SOCIO-DEMOGRAPHIC CHARACTERISTICS OF \\ RESPONDENTS N=497}

\begin{tabular}{|c|c|c|}
\hline $\begin{array}{l}\text { Socio-demographic } \\
\text { variables } \\
\text { Age distribution }\end{array}$ & Number & $\begin{array}{c}\text { Percentages } \\
(\%)\end{array}$ \\
\hline $17-24$ & 115 & 23.1 \\
\hline $25-32$ & 262 & 52.7 \\
\hline $33-40$ & 111 & 22.3 \\
\hline $41-48$ & 9 & 1.8 \\
\hline \multicolumn{3}{|l|}{ Ethic group } \\
\hline Ibibio & 304 & 61.2 \\
\hline Annang & 57 & 11.5 \\
\hline Ibo & 56 & 11.3 \\
\hline Oron & 37 & 7.4 \\
\hline Efik & 16 & 3.2 \\
\hline Others (Hausa, Yorub & a).. 27 & 5.4 \\
\hline \multicolumn{3}{|c|}{ Religion } \\
\hline Christianity & 490 & 98.6 \\
\hline Islam & 5 & 1.0 \\
\hline Traditional & 0 & 0 \\
\hline Others(Ekankar, Amc & orc) 2 & 0.4 \\
\hline \multicolumn{3}{|c|}{ Marital status } \\
\hline Married & 453 & 91.1 \\
\hline Single & 34 & 6.8 \\
\hline Divorced & 4 & 0.8 \\
\hline Widowed & 6 & 1.2 \\
\hline \multicolumn{3}{|l|}{ Educational status } \\
\hline None & 2 & 0.4 \\
\hline Primary & 31 & 6.2 \\
\hline Secondary & 160 & 32.2 \\
\hline Tertiary & 304 & 61.2 \\
\hline \multicolumn{3}{|l|}{ Occupation } \\
\hline Unemployed & 154 & 31.0 \\
\hline Trading & 107 & 21.5 \\
\hline Civil servants & 166 & 33.4 \\
\hline Artisans & 70 & 14.1 \\
\hline \multicolumn{3}{|l|}{ Parity } \\
\hline 0 & 155 & 31.2 \\
\hline 1 & 155 & 31.2 \\
\hline $2-4$ & 171 & 34.4 \\
\hline$>/=5$ & 16 & 3.2 \\
\hline
\end{tabular}

The negative attitude towards CS as a mode of delivery by a small proportion of the population studied should be taken seriously considering its current perceived safety, and its 
proven beneficial effects in reducing maternal and perinatal mortality and morbidity, including long term neurological disability, vesico-vaginal fistula and loss of fertility.

There is therefore the need for proper education of pregnant women on CS, its indications and advantages including its role in reducing maternal and perinatal morbidity and mortality in our environment. Our society needs further enlightening on the advantages of antenatal care attendance and hospital deliveries as the problem is rooted in our culture even as recommendations to local, state and federal governments on the importance of free and compulsory maternity services through an all-inclusive National Health Insurance Scheme will remove the aversion imposed by cost.

In conclusion, our study population showed a strong positive attitude towards CS. This is against the wide assertion of aversion to CS by parturients in developing countries. Even though, this finding is encouraging, all attempts must be made to make it totally acceptable through proper health education, especially during antenatal care and preoperative counselling. We also recommend similar studies to be carried out across other geopolitical zones as well as inclusion of an assessment of opinion on CS in the next National demographic and health survey. This will give the true National view of the attitude and perception towards this procedure.

TABLE II: KNOWLEDGE OF CAESAREAN SECTION N=497

\begin{tabular}{lr}
\hline Variable & $\mathbf{N}(\%)$ \\
\hline Operation to deliver a baby & $427(85.9 \%)$ \\
Mode of delivery to deprive a & \\
woman the right to womanhood & $40(8.1 \%)$ \\
Don't know & $21(4.2 \%)$ \\
Operation to remove the womb & $7(1.4 \%)$ \\
Operation to stop childbirth & $1(0.2 \%)$ \\
\hline
\end{tabular}

\section{TABLE III: REASONS FOR}

SUPPORTING/ ACCEPTING

CAESAREAN SECTION N=446(89.7\%)

\begin{tabular}{lr}
\hline Variable & N (\%) \\
\hline $\begin{array}{l}\text { It is a safer mode of delivery } \\
\text { when normal delivery cannot }\end{array}$ & \\
be achieved & $428(96.0 \% \mathrm{~s})$ \\
To avoid stress of normal & \\
delivery & $9(2.0 \%)$ \\
To please health workers & $6(1.3 \%)$ \\
No reason & $3(0.7 \%)$ \\
\hline
\end{tabular}

TABLE IV: REASONS FOR OPPOSING CAESAREAN SECTION N=51(10.3\%)

\begin{tabular}{ll}
\hline Variable & N (\%) \\
\hline Fear of death & $17(33.3 \%)$ \\
It is a denial of womanhood & $12(23.5 \%)$ \\
Possibility of being exposed & \\
to insults & $10(19.6 \%)$ \\
Culture forbids it & $7(13.7 \%)$ \\
It's the devils work & $6(11.8 \%)$ \\
It's in Doctor's self-interest & $4(7.8 \%)$ \\
It is expensive & $3(5.9 \%)$ \\
No reason & $2(3.9 \%)$ \\
\multicolumn{2}{l}{ Some gave more than one reason } \\
\hline
\end{tabular}

\section{REFERENCES}

1. Betran AP, Merialdi M, Lauer JA, BingShun W, Thomas J, Look PV, Wagner M. Rates of Caesarean section: analysis of global, regional and national estimates. Paed Perinatal Epiderm. 2007; 21(2): 98 113.

2. Bonney EA, Myers JE. Caesarean section: techniques and complications. Obstet. Gynaecol Rep Med 2010; 21(4): 97 - 102 [http://.dx.doi.org/10.1016/j.ogrm.2010.1 2.002]

3. Dolan TG. The lure of Caesarean sections. For the record. 2005; (17), 18: 34.

4. Penna L. Caesarean section on request for non-medical indications. Current Obstet. Gynaecol. 2004; 14: 220-223.

5. Coleman VH, Lawrence H, Schulkin J. 
Rising Cesarean Delivery Rates.The Impact of Cesarean Delivery on Maternal Request. CME review article 4. Obstet.1Gynecol survey. 2009; 64: 2

6. Dumon At, Bernis L, Bouvier-Colle MH Bréart $G$ Caesarean section rate for maternal indication in sub-Saharan Africa: a systematic review Lancet 2001;? 358: 1328-334

7. Ezechi OC, Fasuba OB, Kalu BE, Nwokolo CA, Obiesie LO. Caesarean Delivery: Why the aversion? Trop J ObstetGynaecol. 2004; 21 (2): 164-167.

8. Etuk SJ, Ekanem AD. Socio-demographic and Reproductive Characteristics of women who default from orthodox obstetrics care in Calabar, Nigeria. Int. J. Gynaecol. Obstet. 2001; 73: 57-60.

9. WHO, UNICEF, and UNFPA, 'maternal Mortality in 2000: Estimates developed by WHO, UNICEF and UNLPA 2000.

10. Reproductive Health basics: Safe Motherhood and Emergency Obstetric Care. November 2004 update.

11. Lupton M. Consent and the Law. Current Obstet. Gynaecol. 2004; 14: 363-367.

12. Dass M. Consent and caesarean section. Current Obstet. Gynaecol. 2005; 15: 6064.

13. Onah HE. Formal education does not improve the acceptance of cesarean section among pregnant Nigerian women. IJOG 2002; 76:321-323.

14. Onah HE, Ugona MC. Preference for Caesarean section or symphysiotomy for obstructed labour among Nigerian women. IJOG 2004; 84: 70-91.

15. Chigbu C, Iloabachie G. The burden of Caesarean section refusal in a developing country setting. BJOG: An International Journal of Obstetrics \& Gynaecology 2007; 114: 1261 - 1265

16. Aziken M, Omo-Aghoja L, Okonofua F. Perceptions and attitudes of pregnant women towards caesarean section in urban Nigeria. ActaObstetGynecol Scand. 2000; 86(1): 42 - 47.

17. Awoyinka BS, Ayinde OA, Omigbodun AO. Acceptability of Caesarean delivery to Antenatal patients in a tertiary health facility in south west Nigeria. J ObstetGynaecol. 2006; 26(3); 208-210.

18. Orji EO, Ogunniyi SO, Onwudiegwu U. Beliefs and perceptions of pregnant women at Ilesa about Caesarean section. Trop J ObstetGynaecol. 2003; 20 (2): 141-143.

19.Tatar M, Gunalp S, Somunoglu S, Demirol A. Women's perceptions of Ceasarean section: reflections from a Turkish teaching hospital. SocSci Med. 2000; 50: 12271233. 